\title{
PERBANDINGAN METODE ADAPTIVE MINIMUM ERROR LEAST SIGNIFICANT BIT REPLACEMENT (AMELSBR) DAN DISCRETE COSINE TRANSFORM (DCT) UNTUK STEGANOGRAFI CITRA DIGITAL
}

\author{
${ }^{1}$ Fajar Sidik, ${ }^{2}$ Wamiliana dan ${ }^{3}$ Febi Eka Febriansyah \\ ${ }^{1}$ Jurusan Ilmu Komputer \\ Fakultas Matematika dan Ilmu Pengetahuan Alam \\ Universitas Lampung \\ Jl. S. Brodjonegoro No. 1, Bandar Lampung, 35145
}

\begin{abstract}
Insertion of secret messages with steganography is one way to hide secret messages. In this research we will compare AMELSBR and DCT methods based on web application using image as the media for hiding the secret message. The file format used are (.png) as input cover and stegoimage, and (.txt) as data inserted. The result shows that AMELSBR method better than DCT method for manipulation of brightness, contrast, and cropping.
\end{abstract}

Keywords : amelsbr, dct, steganography

\section{Pendahuluan}

Media digital sekarang adalah media yang lumrah digunakan saat ini. Dengan perkembangannya yang semakin pesat, media digital telah memudahkan seseorang untuk berinteraksi dengan orang lain. Media juga banyak rupanya, dapat berupa surat, gambar, video atau suara sekalipun. Terdapat masalah yakni amankah pengiriman data sampai ke yang dituju atau tidak. Oleh karena itu, penelitian menemukan caranya untuk menjaga data tersebut dengan metode yang dinamakan steganografi. Steganografi adalah satu teknik penyembunyian pesan pada suatu media misalnya media berupa gambar, suara dan lainnya.

Pada penelitian ini akan dibandingkan dua metode yaitu metode AMELSBR (Adaptive Minimum Error Least Significant Bit Replacement) dan DCT (Discrete Cosine Transform). Untuk AMELSBR, sifat metode ini beradaptasi dengan media yang digunakan sebagai cover. Sedangkan DCT, metode ini pada dasarnya akan merepresentasikan suatu citra menjadi jumlahan dari gelombang sinusoidal yang berbeda frekuensi dan magnitudo. DCT juga sering digunakan sebagai kompresi citra. Transformasi ini digunakan sebagai dasar pengembangan kompresi JPEG yang sudah sering digunakan pada saat ini.

Pada penelitian ini akan digunakan gambar dengan jenis file .png untuk cover dan stegoimage. Disisipkan berupa file .txt. Untuk cover dan stegoimage digunakan file .png karena jenis file menggunakan kompresi yang rendah yang dapat mengurangi noise pada gambar saat file .txt sudah disisipkan serta untuk membandingkan besar file sebelum dan sesudah terjadi proses embedding. Implementasi penelitian aplikasi steganografi ini berbasis web karena pengguna 
Vol 6 No. 1, 2018

(C)2018 Ilmu Komputer Unila Publishing Network all right reserve

Jurnal Komputasi

dapat mudah menggunakan komputer atau laptop sehingga data rahasia yang akan dikirim tadi dapat mudah diproses menjadi stego image

\section{Steganografi dan Citra Digital}

\subsection{Steganografi}

Steganography (steganografi) merupakan seni untuk menyembunyikan pesan rahasia kedalam pesan lainnya sedemikian rupa sehingga membuat orang lain tidak menyadari adanya sesuatu di dalam pesan tersebut. Kata Steganography berasal dari bahasa Yunani, yaitu gabungan dari kata steganos (tersembunyi atau terselubung) dan graphein (tulisan atau menulis), sehingga makna Steganography kurang lebih bisa diartikan sebagai menulis tulisan yang tersembunyi [1]

Terdapat dua tahapan umum dalam steganografi digital, yaitu proses embedding atau encoding (penyisipan) dan proses extracting atau decoding (pemekaran atau pengungkapan kembali (reveal). Hasil yang didapat setelah proses embedding atau encoding disebut stego object (apabila media penampung hanya berupa data citra maka disebut stego image) [2]

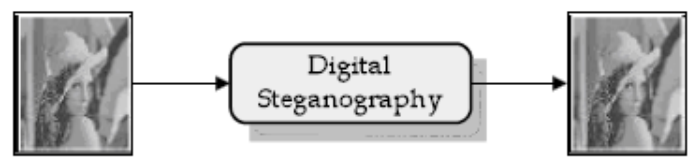

Gambar 1 Steganografi [2]

Steganografi adalah ilmu dan seni menyembunyikan dalam komunikasi. Sistem steganografi ini menyisipkan konten pada suatu media tanpa menimbulkan kecurigaan. Tujuan modern steganografi adalah untuk menjaga data rahasia tidak terdeteksi dengan media penutup (cover). Media tersebut dapat terlihat perbedaannya dengan menemukan distorsi pada media, proses menemukan distorsi ini disebut steganalysis statistik. [3]

\subsection{Citra Digital}

Citra atau gambar dapat didefinisikan sebagai sebuah fungsi yang terdiri dari dua variabel $f(x, y)$, dengan $\mathrm{x}$ dan $\mathrm{y}$ adalah koordinat bidang datar, dan harga fungsi f disetiap pasangan koordinat $(\mathrm{x}, \mathrm{y})$ disebut intensitas atau level keabuan (grey level) dari gambar dititik itu. Jika $\mathrm{x}, \mathrm{y}$ dan $\mathrm{f}$ semuanya berhingga (finite), dan nilainya diskrit, maka gambarnya disebut citra digital (gambar digital). Suatu citra digital terdiri dari sejumlah elemen berhingga, dimana masing-masing mempunyai lokasi dan nilai tertentu. Elemen-elemen ini disebut sebagai picture element, image element, pels atau pixels [4]. Pada [5] dinjelaskan bahwa nilai dari intensitas bentuknya atau level keabuan adalah diskrit mulai dari 0 sampai 255. Citra yang ditangkap oleh kamera dan telah dikuantisasi dalam bentuk nilai diskrit disebut dengan citra digital (digital image).

\subsection{Metode AMELSBR}

Metode ini pertama kali diperkenalkan oleh Lee dan Chen [6]. Lee dan Chen menerapkan citra hitam-putih (grayscale image) sebagai media penampung (cover image) dan kemudian pada tahun Gan [7] mengimplementasikan metode ini dengan citra berwarna 24 bit (true colors image) 
sebagai media penampungnya. Dengan metode ini, setiap pixel memiliki kapasitas penyembunyian yang berbeda-beda tergantung dari nilai toleransi pixel tersebut terhadap proses modifikasi atau penyisipan. Suatu pixel pada data citra bisa dikatakan dapat ditoleransi apabila dilakukan proses modifikasi (penyisipan) dengan skala yang tinggi terhadap nilainya adalah memungkinkan tanpa merubah tampak asli dari data citra tersebut. [7]

Metode AMELSBR yang diterapkan pada citra berwarna (jpg/jpeg 24-bit) memiliki beberapa langkah atau tahapan utama untuk melakukan proses penyisipan, antara lain Capacity Evaluation, MER dan Error Diffusion. [7] Untuk proses pengungkapan, tahapan yang dilakukan yaitu Capacity Evaluation. Sebelum dilakukan proses penyisipan, maka langkah pertama yang harus dilakukan adalah mengevaluasi kapasitas penyisipan (capacity evaluation) dan mencari nilai color variation. Kemudian setelah mendapatkan nilai color variation, nilai tersebut diproses kembali untuk mendapatkan kapasitas penyisipan sejumlah K-bit. Setelah itu, untuk beradaptasi dengan karakteristik lokal pixel, maka sejumlah $K$-bit tersebut ditangani dengan proses evaluasi kapasitas (capacity evaluation). Proses selanjutnya adalah mencari $M E R$, dimana proses ini akan menentukan apakah bit ke $K+1$ akan dilakukan perubahan atau tidak, dan yang akan menentukan itu adalah berdasarkan pada nilai embedding error (Er). Proses tersebut disajikan pada Gambar 2

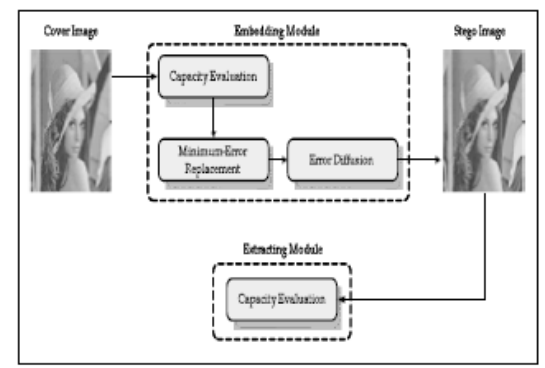

Gambar 2.4 Gambaran Umum Metode AMELSBR. [7]

Proses penyisipan (embedding) di dalam metode AMELSBR, prosesnya tidak sama dengan metode LSB. Apabila proses penyisipan di dalam metode LSB dilakukan langsung per pixel pada byte-nya, dimana 1 bit terakhir (LSB) per byte-nya diganti dengan 1 bit data rahasia yang akan disisipkan, tetapi tidak dengan metode AMELSBR. Di dalam metode ini, citra penampung (cover image) akan dibagi dulu menjadi beberapa blok. Setiap blok akan berukuran 3 x 3 pixel atau sama dengan 9 pixel [8] Ketiga tahapan utama akan diterapkan per bloknya atau per operasi penyisipannya, dimana bit-bit data rahasia hanya akan disisipkan pada salah satu komponen warna di pixel P, dan disajikan pada Gambar 3

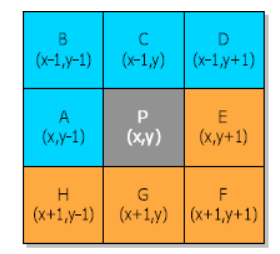

Gambar 3 Pixel Tetangga dari Pixel P [6]

Capacity evaluation, merupakan tahap pertama dari metode penyisipan AMELSBR. Tahap ini mengacu pada karakterisitik human visual system (HVS) yang tidak sensitif terhadap noise dan 
Vol 6 No. 1, 2018

(C)2018 Ilmu Komputer Unila Publishing Network all right reserve

Jurnal Komputasi

perubahan warna yang terdapat di dalam citra [6]. Langkah pertama yang akan dilakukan pada evaluasi kapasitas adalah mencari nilai variasi warna (V) yang melibatkanpixelA, $B, C$ dan $D$. [7]

Persamaan (1) $V$ adalah sebagai berikut

$V=$ round $\{(|C-A|+|A-B|+|B-C|+|C-D|) / 4\}$

$K=\operatorname{round}(|\log 2 V|)$

Rumus tersebut akan menghasilkan ketentuan toleransi modifikasi yang akurat di setiap pixelP. Langkah ke-dua adalah mencari kapasitas penyisipan (K) pada pixelP [7]

Tahap selanjutnya adalah mencari MER. Proses MER dilakukan dengan mengubah nilai bit ke $K+1$ pada pixel $P$. Perubahan ini akan terjadi pada salah satu dari ke-tiga komponen warna (R, $\mathrm{G}$ atau B) yang terpilih [6]. Proses ini disajikan pada Gambar 4

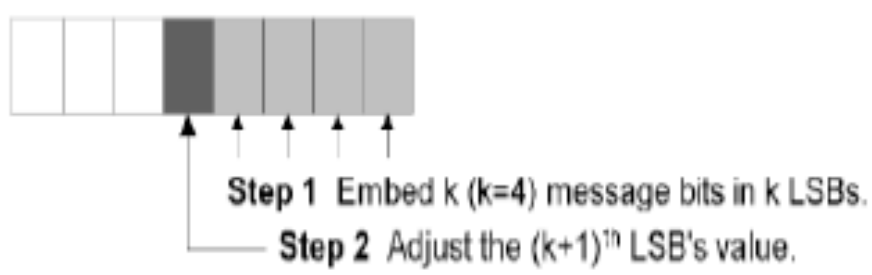

Gambar 4 Proses MER [6]

Lalu bit yang ke-lima akan diubah nilainya, misal nilai awal adalah 1, maka akan diubah menjadi 0 , begitu juga sebaliknya. Namun demikian pengubahan bit ke $K+1$ belum tentu dilakukan, karena pada tahap MER juga dilakukan proses pengecekan nilai embedding error. Embedding error (Er) adalah selisih nilai (dalam desimal) pada komponen warna yang terpilih di pixel $P$, sebelum (original) dan sesudah dilakukan proses penyisipan, atau dengan rumus seperti di bawah ini

$E r=A b s\left[P(x, y)-P^{\prime}(x, y)\right]$

Pengubahan pada bit ke $K+1$ akan dilakukan apabila nilai embedding error memenuhi syarat pada saat pengecekan, uraiannya bisa dijelaskan sebagai berikut. Asumsi $P(x, y)$ adalah pixel $P$ original, $P^{\prime}(x, y)$ adalah pixel $P$ yang telah disisipkan sejumlah $K$-bit tanpa mengubah bit ke $K+1$ dan $P$ ” $(x, y)$ adalah pixel $P$ yang telah disisipkan sejumlah $K$-bit sekaligus mengubah bit ke $K+1$. Minimum error yang dapat terjadi di pixel $P$ haruslah $P^{\prime}(x, y)$ atau $P$ ' $(x, y)[6]$

Kemudian proses pengecekan nilai embedding error dilakukan lewat rumus sebagai berikut

$$
\begin{aligned}
& E r 1=A b s\left[P(x, y)-P^{\prime}(x, y)\right] \\
& \operatorname{Er} 2=A b s\left[P(x, y)-P^{\prime}{ }^{\prime}(x, y)\right]
\end{aligned}
$$


Apabila $E r 1<E r 2$, maka $P$ ' $(x, y)$ yang akan menggantikan $P(x, y)$. Jika sebaliknya maka $P$ ' $(x, y)$ yang akan menggantikan $P(x, y)[6]$

Menurut Panditatwa di skripsinya yang berjudul "Implemetasi Teknil Steganografi Menggunakan Metode Adaptive Minimum Error Least Significant Bit Replacement (AMELSBR)” AMELSBR ini metode yang baik untuk melakukan teknik steganografi. File citra gambar yang digunakan sebagai media penampung (cover) berhasil menyembunyikan atau menyisipkan data khususnya berkas tanpa terlihat mencurigakan dan terlihat seperti file gambar biasa atau tidak ada perbedaannya dengan gambar lain [9].

\subsection{Metode DCT}

Discrete Cosine Transform (DCT) biasa digunakan untuk mengubah sebuah sinyal menjadi komponen frekuensi dasarnya. DCT pertama kali diperkenalkan oleh Ahmed, Natarajan dan Rao pada tahun 1974 dalam makalahnya berjudul "On image processing and a discrete cosine transform [11]

DCT mempunyai dua sifat utama untuk kompresi citra dan video yaitu :

- Mengkonsentrasikan energi citra ke dalam sejumlah kecil koefisien (energy compaction).

- Meminimalkan saling ketergantungan diantara koefisien-koefisien (decorrelation).

DCT dirumuskan sebagai berikut :

$$
\begin{gathered}
\mathrm{S}(\mathrm{u})=\sqrt{2 / \mathrm{n}} \\
C(u)=\sum_{x=0}^{n-1} \cos \frac{(2 \mathrm{x}+1) \mathrm{u} \pi}{2 \mathrm{n}} \\
\text { dengan } u=0, \ldots, n-1 \\
C(u)=\left\{\begin{array}{cc}
2^{-1 / 2}, \text { untuk } u=0 \\
1, & \text { untuk lainnya }
\end{array}\right.
\end{gathered}
$$

Setiap elemen dari hasil transformasi S(u) merupakan hasil dot product atau inner product dari masukan s(x) dan basis vektor. Faktor konstanta dipilih sedemikian rupa sehingga basis vektornya orthogonal dan ternormalisasi. DCT juga dapat diperoleh dari produk vektor (masukan) dan $\mathrm{n} x$ $\mathrm{n}$ matriks orthogonal yang setiap barisnya merupakan basis vektor[11].

\section{Perancangan Sistem (System Design)}

\subsection{Activity Diagram}

Activity diagram menggambarkan aliran kerja (workflow) dari kejadian use case sistem. Gambar 6 adalah diagram aktivitas yang berhubungan dengan aliran kejadian untuk use case sistem teknik steganografi dengan metode AMELSBR (Adaptive Minimun Error Least Significant Bit 
Replacement) dan DCT ( Discrete Cosine Transform). Activity diagram pada sistem ini terbagi atas 2 bagian yaitu activity diagram untuk pengirim dan activity diagram untuk penerima.

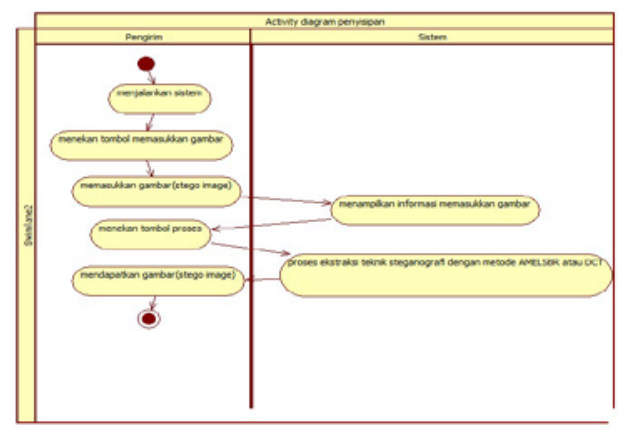

(a)

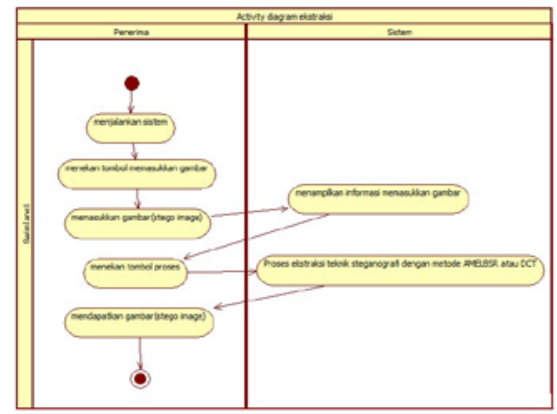

(b)

Gambar 6 Gambar Activity Diagram Aplikasi

\subsection{Sequence Diagram}

Sequence diagram digunakan untuk menunjukkan aliran fungsionalitas dalam use case. Pada sistem ini terdapat 2 bagian sequence diagram yaitu diagram untuk pengirim dan diagram untuk penerima, sesuai dengan use case diagram yang telah digambarkan. Sequence diagram sistem disajikan pada Gambar 7.

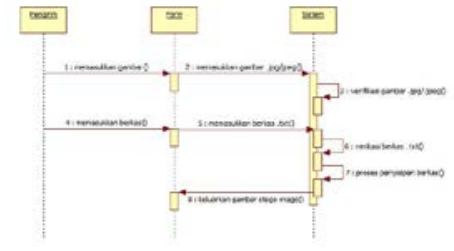

(a)

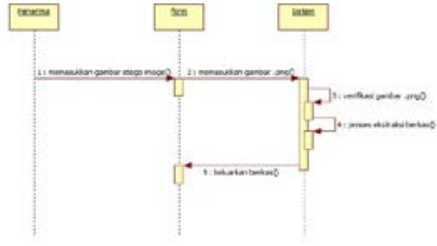

(b)

Gambar 7 Gambar Sequence Diagram Aplikasi

\section{Hasil dan Pembahasan}

\subsection{Implementasi Sistem}

Implementasi teknik steganografi dengan metode AMELSBR (Adaptive Minimum Error Least Significant Bit Replacement) dan DCT (Discrete Cosine Transform) pada penelitian ini dilakukan dengan pengembangan sistem berbasis web yang bertujuan untuk memberikan keamanan dalam penyisipan data berupa berkas dengan media gambar sebagai media penampung.

\subsection{Pengujian Manipulasi Citra Gambar}

Tahap Testing atau tahap pengujian merupakan tahap lanjutan setelah tahap implementasi selesai dilakukan. Tahap ini bertujuan untuk mengetahui apakah sistem sudah berjalan dengan baik dan sesuai harapan. Tahap pengujian pada sistem ini berjalan sesuai dengan rencana pengujian yang 
telah ditetapkan sebelumnya, berikut hasil pengujian sistem implementasi teknik steganografi dengan metode AMELSBR dan DCT. Pengujian ini ditujukan pada output dari implementasi teknik steganografi yaitu disebut dengan stego image. Pengujian dengan manipulasi file citra gambar dibagi menjadi 2 yaitu berupa perubahan pada brightness dan contrast, pengujian ini bertujuan untuk membuktikan bahwa gambar yang telah dilakukan perubahan terhadap brightness dan contrast apakah berkas dapat kembali secara utuh, kembali sebagian atau tidak dapat kembali lagi.

Dalam pengujian ini digunakan 5 file gambar berformat (.png) dengan perbedaan ukuran disetiap file gambarnya. Interval perubahan brightness dan contrast yaitu -150, -120, -90, -60, -30, 30, 60, 90, 120, 1505 file gambar berformat (.png) berserta keterangan disajikan pada Tabel 1

Table 1. Lima File Gambar Berformat (.png)

\begin{tabular}{|c|c|c|c|c|}
\hline NO. & $\begin{array}{l}\text { Gambar } \\
\text { (.png) }\end{array}$ & $\begin{array}{l}\text { Ukuran } \\
\text { Gambar (cm) }\end{array}$ & $\begin{array}{l}\text { Ukuran } \\
\text { Gambar } \\
\text { (pixel) }\end{array}$ & $\begin{array}{l}\text { Ukuran } \\
\text { Gambar } \\
\text { (KB) }\end{array}$ \\
\hline \multicolumn{5}{|l|}{1.} \\
\hline & & $5,44 \times 4,15$ & $257 \times 196$ & 25,2 \\
\hline \multicolumn{5}{|l|}{2.} \\
\hline & & $13,23 \times 8,54$ & $500 \times 323$ & 480 \\
\hline \multicolumn{5}{|l|}{3.} \\
\hline & & $2,96 \times 1,85$ & $350 \times 218$ & 87,1 \\
\hline \multicolumn{5}{|l|}{4.} \\
\hline & & $16,23 \times 10,8$ & $460 \times 306$ & 195 \\
\hline \multicolumn{5}{|l|}{5.} \\
\hline & & 1778 x 873,76 & $700 \times 344$ & 549 \\
\hline
\end{tabular}

File yang disisipkan pada gambar adalah file dengan format (.txt) berukuran 76 bytes yang berisi “ The Quick Brown Fox Jumps Over the Lazy Dog,.;'[]<>?:" \{\} $\mid=-$ _+)(*\&^\%\$\#@! 1234567890 ” Kalimat The Quick Brown Fox Jumps Over the Lazy Dog adalah kalimat istilah yang mencakup semua alfabet dari a-z, setelah kalimat istilah tersebut terdapat semua tanda baca dan karakter pada penulisan serta angka.

Proses manipulasi pada implementasi teknik steganografi dengan metode AMELSBR dan DCT dapat tahan terhadap proses manipulasi gambar (stego image) mempunyai kemungkinan pengembalian berkas paling banyak dengan perubahan brightness sebesar -150, -90, -60, -30, 30, 60, 150 pada Gambar 1 dan 3 dibandingkan dengan ketiga gambar lainnya yang sama sekali tidak dapat mengembalikan berkas. Berikut ulasan pengujian dengan perubahan brightness dapat dilihat pada Tabel 2 dan Tabel 3. 
Tabel 2. Ulasan Pengujian Perubahan Brightness AMELSBR

\begin{tabular}{|l|l|l|l|l|l|l|l|l|l|l|}
\hline \multirow{2}{*}{ No Gambar } & \multicolumn{6}{|l|}{ Perubahan Brightness } \\
\cline { 2 - 11 } & -150 & -120 & -90 & -60 & -30 & 30 & 60 & 90 & 120 & 150 \\
\hline Gambar 1 & & & & & & & & & & \\
\hline Gambar 2 & & & & & & & & & & \\
\hline Gambar 3 & & & & & & & & & & \\
\hline Gambar 4 & & & & & & & & & & \\
\hline Gambar 5 & & & & & & & & & & \\
\hline
\end{tabular}

berkas tidak kembali $\square$ berkas kembali $\square$ berkas kembali namun tidak lengkap

Tabel 3. Ulasan Pengujian Perubahan Brightness DCT

\begin{tabular}{|l|l|l|l|l|l|l|l|l|l|l|}
\hline \multirow{2}{*}{ No Gambar } & \multicolumn{6}{|l|}{ Perubahan Brightness } \\
\cline { 2 - 9 } & -150 & -120 & -90 & -60 & -30 & 30 & 60 & 90 & 120 & 150 \\
\hline Gambar 1 & & & & & & & & & & \\
\hline Gambar 2 & & & & & & & & & & \\
\hline Gambar 3 & & & & & & & & & & \\
\hline Gambar 4 & & & & & & & & & & \\
\hline Gambar 5 & & & & & & & & & & \\
\hline
\end{tabular}

\section{berkas tidak kembali} berkas kembali berkas kembali namun tidak lengkap

Dari Tabel 2 dan Tabel 3. dapat disimpulkan bahwa perubahan tingkat kecerahan pada stego image yang dilakukan pada 5 gambar tersebut tidak semuanya dapat mengembalikan berkas yang disisipi sebelumnya,

Pada pengujian manipulasi stegoimage pada implementasi teknik steganografi dengan metode Discrete Cosine Transform (DCT) dan AMELSBR dengan melakukan perubahan contrast, Berikut ulasan pengujian dengan perubahan contrast dapat dilihat pada Tabel 4. dan Tabel 5.

Tabel 4.Ulasan Pengujian Perubahan Contrast AMELSBR 
(c2018 Ilmu Komputer Unila Publishing Network all right reserve

\begin{tabular}{|l|l|l|l|l|l|l|l|l|l|l|}
\hline \multirow{2}{*}{ No Gambar } & \multicolumn{6}{|l|}{ Perubahan Contrast } \\
\cline { 2 - 10 } & -150 & -120 & -90 & -60 & -30 & 30 & 60 & 90 & 120 & 150 \\
\hline Gambar 1 & & & & & & & & & & \\
\hline Gambar 2 & & & & & & & & & & \\
\hline Gambar 3 & & & & & & & & & & \\
\hline Gambar 4 & & & & & & & & & & \\
\hline Gambar 5 & & & & & & & & & & \\
\hline
\end{tabular}

Tabel 5. Ulasan Pengujian Perubahan Contrast DCT

\begin{tabular}{|l|l|l|l|l|l|l|l|l|l|l|}
\hline \multirow{2}{*}{ No Gambar } & \multicolumn{6}{|l|}{ Perubahan Contrast } \\
\cline { 2 - 11 } & -150 & -120 & -90 & -60 & -30 & 30 & 60 & 90 & 120 & 150 \\
\hline Gambar 1 & & & & & & & & & & \\
\hline Gambar 2 & & & & & & & & & & \\
\hline Gambar 3 & & & & & & & & & & \\
\hline Gambar 4 & & & & & & & & & & \\
\hline Gambar 5 & & & & & & & & & & \\
\hline
\end{tabular}

berkas tidak kembali $\square$ berkas kembali $\square$ berkas kembali namun tidak lengkap

Dari Tabel 4 dan tabel 5 dapat disimpulkan bahwa Pada perubahan contrast gambar yang mempunyai kemungkinan pengembalian berkas paling banyak dengan perubahan contrast sebesar -150, -120, -90, -60, -30, 30, 60. Terbukti untuk pengujian ini, AMELSBR lebih baik dalam pengembalian pesan dari DCT karena lebih banyak berkas yang kembali secara utuh.

Pada pengujian pemotongan gambar dapat disimpulkan bahwa metode AMELSBR dan DCT melakukan penyisipan tulisan di dalam berkas pada bagian atas gambar. Berikut ulasan pengujian dengan pemotongan gambar (cropping) dapat dilihat pada Tabel 6 
Tabel 6 dan 7. Ulasan Pengujian Pemotongan Gambar (Crop) AMELSBR \& DCT

\begin{tabular}{|l|l|l|l|l|l|}
\hline \multirow{2}{*}{ No Gambar } & \multicolumn{5}{|c|}{ Pemotongan Gambar (Crop) } \\
\cline { 2 - 6 } & Kanan & Kiri & Atas & Bawah & Seluruh \\
\hline Gambar 1 & & & & & \\
\hline Gambar 2 & & & & & \\
\hline Gambar 3 & & & & & \\
\hline Gambar 4 & & & & & \\
\hline Gambar 5 & & & & & \\
\hline
\end{tabular}

\begin{tabular}{|l|l|l|l|l|l|}
\hline \multirow{2}{*}{ No Gambar } & \multicolumn{5}{|c|}{ Pemotongan Gambar (Crop) } \\
\cline { 2 - 6 } & Kanan & Kiri & Atas & Bawah & Seluruh \\
\hline Gambar 1 & & & & & \\
\hline Gambar 2 & & & & & \\
\hline Gambar 3 & & & & & \\
\hline Gambar 4 & & & & & \\
\hline Gambar 5 & & & & & \\
\hline
\end{tabular}

berkas tidak kembali berkas kembali

$\square$ berkas kembali namun tidak lengkap

Dari Tabel 6 dan Tabel 7 dapat disimpulkan bahwa pemotongan pada stego image yang dilakukan pada 5 gambar tersebut tidak semuanya dapat mengembalikan berkas yang disisipi sebelumnya. Pada metode AMELSBR dan DCT, hanya bagian kanan dan bawah yang dapat mengembalikan berkas teks.

\section{Kesimpulan}

Kesimpulan yang dapat diambil dari penelitian ini adalah Kedua metode AMELSBR dan DCT adalah metode yang baik yang digunakan untuk menyimpan pesan rahasia dengan baik. AMELSBR lebih unggul dalam ketahanan menjaga pesan rahasia ketimbang DCT dengan dapat mengembalikan pesan rahasia pada sejumlah percobaan. Sistem implementasi teknik steganografi dengan metode AMELSBR dan DCT ini dapat digunakan dengan baik untuk menyembunyikan berkas di dalam media penampung gambar dan dapat memberikan keamanan dalam pengiriman data. Ketahanan gambar pada manipulasi seperti brightness, contrast, dan cropping ditentukan oleh komposisi warna, metode yang dipakai, dan ukuran gambar. Tidak terlihat perbedaan yang signifikan pada gambar dikarenakan penggunaan format file gambar (.png) sebagai input dan output. Dengan demikian format file (.png) tersebut baik digunakan untuk teknik steganografi.

\section{Daftar Pustaka}

[1] Sellars, D. 2006.An Introduction to Steganography, ,http://www.cs.uct.ac.za/ courses/CS400W/NIS/papers99/dsellars/ stego.html [diakses tanggal 29 Oktober 2015]

[2] Prayudi, Y dan Kuncoro, S. 2005. Implementasi Steganografi Menggunakan Teknik Adaptive Minimum Error Least Significant Bit Replacement (AMELSBR). Program Studi Teknik Informatika, Fakultas Teknologi Industri Universitas Islam Indonesia. Yogyakarta.

[3] Provos, N and Honeyman, P. 2003. Hide and Seek: An Introduction to Steganography. University of Michigan.

[4] Hermawati, Fajar A. 2013. Pengolahan Citra Digital. Yogyakarta : Andi Offset. 
(c2018 Ilmu Komputer Unila Publishing Network all right reserve

[5] Purnomo, Mauridhi H dan Muntasa A. 2010. Konsep Pengolahan Citra Digital dan Ekstrasi Fitur. Yogyakarta : Graha Ilmu.

[6] Lee, Y. K., dan Chen, L. H. 1999. An Adaptive Image Steganographic Model Based on Minimum-Error LSB Replacement, http://citeseer.ist.psu.edu/205600.html/lee99adaptive.pdf. [diakses tanggal 10 Februari 2015]

[7] Gan, M. D. 2003. Chameleon Image Steganography, http://chameleonstego. tripod.com/downloads/Chameleon_Technical_Paper.pdf, [diakses tanggal 10 Februari 2015]

[8] Bailey, K., Curran, K., dan Condell, J. 2004. An Evaluation of Automated Stegodetection Methods In Images,

http://www.ittconference.com/anonftp/pdf/2004\%20presentations/Presentations/session\% 20a/Karen\%20Bailey-1.ppt, [diakses tanggal 28 Oktober 2015].

[9] Panditatwa, Pandya. 2015. Implemetasi Teknil Steganografi Menggunakan Metode Adaptive Minimum Error Least Significant Bit Replacement (AMELSBR). Skripsi Strata 1 pada Universitas Lampung. Tidak Diterbitkan.

[10] Ahmed, N., Natarajan, T., \& Rao, K. R. 1974. Discrete Cosine Transform. IEEE Transactions on Computers, C-23(1), 90-93. DOI: 10.1109/T-C.1974.223784.

[11] Watson, Andrew B. 1994. Image Compression Using the Discrete Cosine Transform. Washington D. C. : NASA Ames Research Center : Mathematica Journal. 